\title{
Complex trauma and borderline personality disorder
}

\author{
Joanic Masson*, Amal Bernoussi, Marie Cozette Mience, François Thomas \\ Center of Research of Psychology, University of Picardie Jules Verne, Amiens, France \\ Email: ${ }^{*}$ joanic.masson@u-picardie.fr \\ Received 4 July 2013; revised 3 August 2013; accepted 11 August 2013 \\ Copyright (C) 2013 Joanic Masson et al. This is an open access article distributed under the Creative Commons Attribution License, \\ which permits unrestricted use, distribution, and reproduction in any medium, provided the original work is properly cited.
}

\begin{abstract}
The aim of this article is to bring together the concepts of borderline pathology and complex trauma. We wish to show that the symptomatology characteristic of borderline pathology approaches, is indeed similar to, that of Non-Specific Extreme Stress (NSES) states. Thus the hypothesis is that states of NSES and borderline pathology constitute psychopathological entities which overlap but reflect different paradigms. The former is linked to the field of psychotraumatology while the latter is more rooted in psychoanalytic theory. In this way traumatic etiology opens the way for the clinician to explore new psychotherapeutic strategies.
\end{abstract}

Keywords: Complex Trauma; Borderline Personality; State of Non-Specific Extreme Stress

\section{INTRODUCTION}

The borderline concept is generally linked to psychoanalytic epistemology, which regards the question of absence of structuration as one of the fundamental criteria in differential diagnosis. A whole trend, especially upheld by the paradigm derived from such psychotherapies as EMDR (Eye Movement Desensitisation and Reprocessing), Ego State Therapy or SE (Somatic Experiencing), which recognise potentially traumatic experiences as playing an important role in the onset of psychopathological states, developed in parallel to this perspective. Based on this clinical view, it is possible to envisage a psychotraumatic view of borderline pathology and to be receptive to new possibilities for its understanding and management.

\section{THE PRINCIPAL CHARACTERISTICS OF BORDERLINE PATHOLOGY}

The borderline issue is typically characterised by the

"Corresponding author. anaclitic nature of the subject's relationship to others. This manifests itself in a tendency to affective dependence underscored by abandonment and object loss anxiety. The relationship to another (object or person) is chaotic and ambivalent: dangerous when it is too close, distressing when the other is far away or absent. The direct psychopathological consequence of this tendency is a permanent threat of depression linked to fragile selfesteem. The fragility of the Ego manifests itself through a lack of instinctual/emotional control as well as the inability to tolerate those frustrations which echo this lack. This operating mode is linked to the relationship system which has been experienced by the subject within the family unit (developmental ecosystem). Through the notion of character structure, Lowen [1] describes how unfulfilled needs (the need for love, for security, etc.) shape both the subject's identity and body image. This population type, for whom the sentiment of abandonment and object loss is omnipresent in both the body and the mind, is characterised by the oral character structure. The work of Winnicott [2], and his concepts of holding and handling reinforces this point of view and stresses the destructuring force of a lack of support and protection during identity development. Character adjustment (Bergeret, [3]) develops when the ardent imagined desire for the mothering image is repressed before the need for such support has been sufficiently satisfied, due to the psychic or corporal absence of the individualised and psychic representation of the nurturing and mothering figure. The child must become prematurely independent, which brings about a conflict between the need for recognition on the one hand, and fear of annihilation on the other. Anaclitic depression is generally the principal latent symptom of adaptation. Thus, the child, and later through forced social evolution the adolescent and the future adult, takes as a reference and is initiated through pseudo-adaptation to whatever is available within his environment by means of mimicry and compensation. 


\section{BORDERLINE PATHOLOGY, PSYCHIC TRAUMA AND PSYCHOTRAUMATIC SYNDROMES}

On a day to day basis, clinical evidence points to the prevalence of infantile trauma as the source of borderline pathology. Studies confirm the preponderance of life experiences and trauma as the source of depressive syndromes (Debray, [4]): early loss, humiliation, insecurity, negligence, parental separation and conjugopathies. According to Debray, the more severe the trauma, the more severe the borderline pathology (DSM IV). For his part Fourcade [5] envisages an "early psychic trauma" as the principal disorganiser, where the child is confronted with the risk of object loss, usually in the form of the string of microtraumas. Without a doubt, the question of the integration of painful experiences is an implicit etiological factor. Nijenhuis \& colleagues [6], with reference to Myers [7] speak of a structural dissociation between an "Apparently Normal Personality" (ANP) and one or more "Emotional Personalities" (EPs). This dissociation works as an adaptation technique aimed at mastering internal everyday states following an accumulation of traumatic experiences (Van der Hart \& col., [8]). The ANP groups together all affective and voluntary activities which tend towards the avoidance of traumatic memories, whereas the EP remains anchored in the traumatic experiences. This structural dissociation of the personality corresponds to a clinical factor characteristic of borderline pathology.

In view of what has just been described above, certain authors have legitimately established a strong link between borderline pathology and psychotraumatic syndromes. Debray [4] for example puts forward the hypothesis that borderline pathology represents a particular form of psychotraumatic syndrome. In the first instance, this hypothesis rests on a group of common symptoms (affective and thymic instability, risk of depression, susceptibility, impulsiveness, aggressiveness, elements of dissociation in the Janetian sense, even depersonalisation traits). For his part, Lopez [9] stresses the high, although not systematic, prevalence of post-traumatic stress disorders (PTSD) in borderline subjects. The absence of a diagnosis of PTSD in no way rules out the possibility of a non-specific psychotraumatic syndrome, a disorder stemming from a former state of stress. We suggest the term "latent psychotraumatic syndrome" to highlight this psychotraumatic etiology. The "latent psychotraumatic syndrome" reflects an "anxio-depressive" state whose etiology is linked to a series of non-integrated traumatic events lacking the symptomatology typical of PTSD. Day-to-day clinical work indeed confirms the presence of a large number of patient disorders which have their origins in the accumulation of sometimes hardly percep- tible traumatic situations, and which as a rule are not sufficiently taken into account by practitioners. In the light of the remarks of Lowen [1] we may postulate specificity in borderline states which may in turn give rise to a particular typology of psychotraumatic states. Fear of abandonment in particular reflects relational dysfunction of a precise origin in which the parents of the borderline subject maintain anaclitism and prevent any attempt at autonomy. Roques [10] speaks of "psychic poisoning" to describe this specific family atmosphere in which the young child is frequently exposed to relational dysfunction and to stress which, in the absence of any protective measures, will progressively reinforce certain unadapted adaptation patterns.

\section{COMPLEX TRAUMA}

Complex trauma, also known as "DESNOS" (Disorder of Extreme Stress Not Otherwise Specified) is characterised by a group of precise symptoms: emotional dysregulation, finding it difficult - if not impossible- to integrate and render meaningfulpast experiences, identity disorders, somatoformdisorders as well as marked affective dependence. Bourgault [11] for his part describes a dysregulation of conscience with a preponderance of dissociation traits (in the Janetian sense), emotional dysregulation (anger, feelings of emptiness) with difficulty in controlling behaviour (impulsiveness, risk-taking, addictions), numerous cognitive distortions as well as impairment in the manner of relating to others (affective dependence).

According to Forgash \& col. [12], DESNOS characterises an extreme stress disorder and indicates a traumatic adaptation to serious abuse or neglect. A comparison with the notion of "developmental trauma disorder" elaborated by Van der Kolk [13] accordingly reinforces the idea of the etiological impact of the socio-psychobiological environment: early and repeated exposure to a toxic atmosphere, disrupted parental attachment, feelings of abandonment as well as a sense of loyalty: the impossibility of taking action, the subjugation of the needs of the victim to the family bond. The toxicity of this environment gives rise to an impairment of systems of signification, to despair and to loss of confidence in the world. Relational problems arise from the difficulty of selfpreservation (isolation and avoidance tendencies). Selfperception is damaged (impaired self-esteem, shame) as is the perception of the perpetrator of violence due to a sense of loyalty in keeping with the subject's pathological beliefs.

The early onset of traumatic events is generally evoked as their main etiological factor. Insecurity and abuse belong to the realm of recognised traumatising situations. The most commondescription is that of affec- 
tive deprivation, giving rise to high levels of aggressiveness, sexual problems in adulthood, permanent feelings of insecurity which cause the subject to be constantly on guard, and hypervigilance (in order to be prepared for the slightest aggression). Frequent addictive behaviours constitute a means of channelling psychotraumatic symptoms, thus allowing the subject to control dysphoric emotional states and dissatisfactions to the best of his or her ability.

For his part, Terr [14] distinguishes between type 1 and type 11 subjects. Type 11 refers to subjects manifesting complex trauma while those belonging to type 1 have been subjected to a "single-blow" trauma, which presents a clearly defined beginning and end. Psychotraumatic syndromes are often the result of these events (mugging, rape, car accident, natural disasters, fire). As for type 11 subjects, they have experienced repeated traumatising situations, placing them in a position of constant threat. The causal factor of stress is thus both long-standing and repeated (domestic violence, incest, torture, etc.) The care of patients suffering from complex trauma emphasises this type 11 typology (which features insecurity, attachment disorders, humiliation and impaired self-esteem, violence which is often sexual in nature, damaged psychological integrity, denial of desires, etc.).

\section{BORDERLINE PATHOLOGY AND COMPLEX TRAUMA}

What emerges from these studies is the evidence of a close link between complex trauma and borderline pathology. DESNOS indeed constitutes an umbrella term for a group of psychopathological traits common to borderline pathology: emotional dysregulation, finding it difficult - if not impossible - to integrate and render meaningful past experiences, identity disorders, somatoform disorders as well as marked affective dependence. The notion of complex trauma derives from the fact that the preponderance of these symptoms fluctuates greatly within time, space and socio-familial situations. The anaclitic nature of elaborate inter-relational dependency shot through with a false social self and abandonment anxiety is again to be seen. A fragile identity structure and pathogenic self-esteem, now weak and depressive, now crushing and omnipotent mean a permanent threat of depression. A lack of emotional control and the presence of harsh personal aspirations and demands are indicative of unease and discomfort as regards behaviour, cognition and attitudes in relation to others and to society. Depending on age and the type of traumatogenic situations encountered, the resulting pathology will take the form of either a PTSD, a latent psychotraumatic syndrome or a complex trauma. In order to clarify this data we propose looking at a clinical study emanating from our research.

\section{CLINICAL STUDY}

As part of a university study carried out in 2012 (Cozette, [15]), we investigated the psychotraumatic etiology of identity disorder in subjects addicted to opiates. Taking as our starting point the premise of Sztulman $[16,17]$ that all addicts possess a common psychic mode of functioning, regardless of their addiction, we based our study on the assumption, confirmed by several other studies, of the existence of an addictive borderline personality within our population. Catteeuw for example found that nearly $75 \%$ of his sample, suffering from polytoxicomania, showed evidence of borderline functioning. For his part, Bernoussi [18] observed that $92 \%$ of his sample of cannabis addicts belonged to the same category.

\section{METHODS}

Our sample was made up of 15 subjects, 8 men and 7 women, all attending a consultation centre for addicts. The average age for inclusion in the study was fixed at 25 to ensure that consumption experiences came within a similar socio-cultural context. The respective ages ranged from 22 to 34 . The other criteria for inclusion focused on past experience of repeated opiate consumption on the one hand, and experience of long-term withdrawal on the other. Two variables dictated the choice of this period: the first being the necessity of processing of results required by our methodology, which supposed the subject's ability to put his past and present experience into words. The second stemmed from the intrusive character of our research (leading questions relating to the subject's traumatic history), which seemed to us to be incompatible with a daily consumption of heroin-type opiates.

Within the framework of this research we sought to assess the prevalence of complex traumatism on the one hand and a symptomatology indicating a borderline personality and a profile of "insecure" attachment on the other. In order to do this, we drew on our semi-directive interviews, with topics relating to drug use and the symptomatology typical of borderline personality disorder as well as of complex trauma. The questionnaire, based on the CTQ (Childhood Trauma Questionnaire, Paquette \& col., [19]), seeks to assess the presence of an infantile complex traumatism, a pernicious family context and a borderline symptomatology. The questions on the consumption of opiates relate to when they started to be taken, the family and social context at the time, and what form they took. The second part deals more with the emotional experiences of the subject on a daily basis, somatoform disorders, relating to others; we need to assess the presence of a DESNOS. Finally, the last part of the interview touches more specifically on family ties, the feelings of insecurity experienced during childhood 
and the possible absence of adequate, supportive parenting. Lastly, we wished to determine the presence of early and repeated family traumatisms. In order to do this we gave the subjects the following instructions: "Looking back now, what are your five most painful and upsetting childhood memories? Because they evoke in you feelings of either anguish, sadness, guilt, shame or stress $\cdots$ the memories must have something to do with your childhood and your family $\cdots$ they may relate to a fleeting memory, to an image, to a recurrent nightmare, or to something you were told and which you built up into a picture which makes you unhappy when you think of it. For each memory try to pinpoint approximately how old you were at the time. If you do not wish to talk about any particular memory, either because it is too painful or merely because you do not want to share it, just write down that a memory became embedded in your mind at such and such an age, without giving me any details of the memory itself".

\section{RESULTS}

The results recorded (Table 1) show that for fourteen of the subjects the childhood context is characterised by the prevalence of complex traumatisms, indicative of many overwhelming and violent events, beginning for the most part at an early age.

This information confirms the presence of an early traumatism, which can be deemed chronic in the sense that the repeated occurrence of violent situations constitutes a long-standing traumatism that will gradually weaken and destructure the psychological functioning of the subject. For ten of the subjects these complex traumatisms continue into adolescence, and for eight subjects into adulthood. The nature of the traumatisms encountered belongs to the realm of affective loss, neglect and even violence. The loss of a significant other (twelve subjects) serves to render an absence or an effective loss irreversible, annihilating all hope of reforging a link. Physical violence (for ten subjects) constitutes a veritable attack on corporal and psychic identity, paving the way

Table 1. Summary of traumatic experiences documented in the study sample.

\begin{tabular}{lcc}
\hline & $\begin{array}{c}\text { Number of } \\
\text { affected subjects }\end{array}$ & $\begin{array}{c}\text { Percentage of } \\
\text { affected subjects }\end{array}$ \\
\hline $\begin{array}{l}\text { Presence of complex } \\
\text { trauma }\end{array}$ & 14 & $93.3 \%$ \\
$\begin{array}{l}\text { Loss of a significant } \\
\text { person }\end{array}$ & 12 & $80 \%$ \\
Physical violence & 10 & $66 \%$ \\
Psychological violence & 8 & $53.3 \%$ \\
Parental neglect & 6 & $40 \%$ \\
Serious accidents & 5 & $33.3 \%$ \\
\hline
\end{tabular}

for the development of affective, somatic, behavioural and cognitive disorders, as well as those relating to attachment. These are often associated with psychological violence which (for eight subjects) is the main cause of identity disruption, hampering not only psychic and affective life but also social interaction and the ability to relate to others, as well as affecting the values and the references of the child: the extent of the disorders being in direct relation to the importance of the role of the person who was at the root of them. Neglect (for six subjects) leads notably to feelings of abandonment and provokes a loss of developmental guidelines. Lastly, the memories associated with serious accidents (for five subjects) reactivate the feelings of insecurity felt in the presence of attachment models and reinforce such associated negative cognitions as "I am unlovable", "I am alone", "I cannot trust other people", "I am worthless", "I am damaged forever", "I am powerless", etc.

\section{CONCLUSIONS}

The data collected points to the fact that these traumatisms are linked to attachment models. "Insecure" attachment is the most widely remarked link, which gives rise to enormous difficulties in the subject's capacity to regulate emotions, physiology, or identity awareness. In terms of adaptation, by interrupting development or causing it to regress, this sort of attachment actually reinforces the deprivations experienced in childhood. Attachment to the paternal object is also explored, and for eleven subjects the father is either absent or dead, for eight subjects he is idealised and for two subjects he is identified as the aggressor. For twelve of the subjects he is a central traumatic figure: perpetrator of physical violence, sexual abuse, indifference or neglect, or associated with absence or irreversible loss. Lastly, in the light of what has been seen above, all our subjects manifest a highly fragile identity structure, a damaged body image, anaclitic-type depression, and abandonment anxiety. Added to this, we found a lack of mentalisation linked to great difficulty in emotion control.

This study shows the great number of psychopathological and clinical elements common to both borderline pathology and complex trauma: emotional dysregulation, found it difficult, if not impossible, to integrate and render meaningful past experiences, identity disorders, somatoform disorders as well as marked affective dependence. We remark the anaclitic nature of relationships as well as a permanent threat of depression indicative of a fragile identity structure. These subjects' early years are marked by a pernicious familial or social context, paving the way for the emergence of complex traumatisms which prevent the child from the correct construction of his or her identity. Early-onset disorders develop as a consequence of "insecure" attachment ties and 
multiple traumatisms. We witness associated negative beliefs which are reinforced during the development process and through the impairment of cognitive and identity structure systems. The shortcomings of the attachment models lead the child to a false interpretation of him/herself at an early stage: he/she can neither observe his/her image in an absent or traumatic reflection, nor can he/she rely on others to keep his/her emotions in check or make sense of the events around him/her. Others are not the embodiment of regenerating and kindly surroundings, but rather the crystallization of feelings of an external threat.

These observations should serve to guide psychotherapeutic perspectives towards a better understanding of the importance of traumatic factors. We need to assess approaches such as EMDR (Eye Movement Desensitisation and Reprocessing) or Sensory-Motor Therapy as valid treatments for these types of pathology. These psychotherapies rely mainly on the mobilisation of the patient's psychic resources (adaptive information processing model) to encourage a constructive assimilation of those pathogenic memories which have contributed to the etiology of the disorders. Day-to-day treatment of this type of patient, which necessitates rigorous scientific verification, demonstrates that careful and adapted treatment of psychological traumatisms, taking into account the patient's capacity for resilience, allows the abovementioned psychopathological consequences (negative beliefs, dysphoric emotions, somatisations, identity disorders, dysfunctional inter-relational structures) to diminish, or even to disappear altogether. We can observe a veritable reworking of identity together with the development of both psychic resources and an increased capacity to cope with everyday life.

\section{REFERENCES}

[1] Lowen, A. (1979) La Bio-énergie. Sand\&Tchou, Paris.

[2] Winnicott, D.W. (1989) La mère suffisamment bonne. Payot \& Rivages, Paris.

[3] Bergeret, J. (1975). La dépression et les états limites. Payot, Paris.

[4] Debray, Q. (2006) Psycho-traumatologie. Evaluation, clinique, traitement. Dunod, Paris.
[5] Fourcade, J.M. (1997) Les patients limites. Desclee de Brouwer, Paris.

[6] Nijenhuis, E., Van der Hart, O., Steele, K., De Soir, E. and Matthess, H. (2006) Dissociation structurelle de la personnalité et trauma. Stress et Trauma, 6, 125-139.

[7] Myers, C.S. (1940) Shell shock in France 1914-1918. Cambridge UniversityPress, Cambridge.

[8] Van der Hart, O., Nijenhuis, E. and Steele, K. (2009) Souvenirs traumatiques. Leur traitement selon le modèle de la dissociation structurelle de la personnalité. Stress et Trauma, 9, 81-92.

[9] Lopez, G. and Jehel, L. (2006) Psycho-traumatologie. Evaluation, clinique, traitement. Dunod, Paris.

[10] Roques, J. (2007) Guérir avec l'EMDR. Traitement, théorie, témoignages. Editions du Seuil, Paris.

[11] Bourgault, R. (2008) Psycho-traumatologie. L'aide- mémoire. Dunod, Paris.

[12] Forgash, C. and Copeley, M. (2007) Healing the heart of trauma and dissociation with EMDR and ego state therapy. Springer, New York.

[13] Van der Kolk, O. (2008) Developmental trauma disorder: A proposeddiagnosis for DSM V. Interventions for traumatized populations: An expert update from ISTSS. Royal College of Physicians, Londres.

[14] Terr, L. (1994) Unchained memories. BasicBooks, New York.

[15] Cozette, M. (2012) Traumatisation, dissociation structurelle de la personnalité et addiction aux opiacés. Mémoire de Recherche de Master 2, University of Picardie Jules Verne, Amiens.

[16] Sztulman, H. (2001) Vers le concept de personnalités limites addictives. Annales Médico Psychologiques, 159, 201-207. http://dx.doi.org/10.1016/S0003-4487(01)00039-7

[17] Sztulman, H. (2010) Personnalités limites addictives. Unere lecture plurielle. Pensée Plurielle, 23, 37-51.

[18] Bernoussi, A. (1999) Addiction au cannabis etpersonnalitélimite. Ph.D. Psychology, University of Toulouse, Toulouse.

[19] Paquette, D., Laporte, L., Bigras, M. and Zoccolillo, M. (2004) Validation de la version française du CTQ et prevalence de l'histoire de maltraitance. Santé Mentale au Quebec, 29, 201-220. http://dx.doi.org/10.7202/008831ar 